\title{
Evaluation of Rotary File Separation and its Retrieval from Root Canals - An Institutional Based Study
}

Research Article

Roghith Kannan ${ }^{1}$, Adimulapu Hima Sandeep²*, Revathi Duraiswamy ${ }^{3}$

${ }^{1}$ Saveetha Dental College and Hospitals, Saveetha Institute of Medical and Technical Sciences, Saveetha University, Chennai, India.

${ }^{2}$ Senior Lecturer, Department of Conservative Dentistry and Endodontics, Saveetha Dental College and Hospitals, Saveetha Institute of Medical and Technical Sciences, Saveetha University, Chennai, India.

${ }^{3}$ Senior Lecturer, Department of Conservative Dentistry and Endodontics, Saveetha Dental College and Hospitals, Saveetha Institute of Medical and Technical Sciences, Saveetha University, Chennai, India.

\section{Abstract}

One of the most frequent mishaps during root canal treatment is the separation of an endodontic instrument during biomechanical preparation. It prevents proper debridement of the canal apical to the fragment and compromises the prognosis of the treatment. The development in armamentarium and different techniques has led to successful retrieval of separated instruments from the root canal. The main objective of this study was to evaluate rotary file separation and its retrieval from root canals. The current study is an institutional based retrospective study performed over reviewing 6475 case records. A total of 22 subjects who underwent rotary file separation and its retrieval from canals were chosen for the study out of 6475 subjects who had undergone root canal treatment. Patients other than root canal treated cases and medically compromised patients were excluded. Once the data was obtained and verified with the help of photographs, analysis was done by descriptive and inferential statistics using SPSS by IBM version 20. From this current study, it was found that, out of 22 patients, $45.5 \%$ (10) males and $54.5 \%$ (12) females have undergone rotary file retrieval treatment. Highest incidence of rotary file separation and its retrieval was seen in lower molars $36.36 \%$ (8). Considering the site involved, instrument separation was commonly identified in the middle third $(40.91 \%)$ and in the coronal third $(40.91 \%)$ of the root canal. Patients in the age group of 31-40 years had the highest incidence of rotary file separation and retrieval. Adequate knowledge, experience and clinical skill enables good management of fractured instruments in the root canal.

Keywords: Endodontic Mishaps; Molars; Retrieval; Rotary File Separation.

\section{Introduction}

Instrument separation can occur at any stage of root canal treatment while using endodontic instruments like files, spreaders, pluggers. The separation of instruments during endodontic therapy is a troublesome process and its incidence ranges from $2 \%$ to $6 \%$ [1]. Complete cleaning and filling of the root canal system is a very important objective for a successful root canal therapy. Al Nazhan et al., identified that $68 \%$ of endodontic mishaps occur in the posterior teeth with curved roots [2]. The most common causes for file separation are improper use, limitation in physical property, root canal anatomy, inadequate access and manufacturing defects. With respect to root canal curvature, separation frequencies rise up to increased curvature, $7 \%$ in straight canals, $35 \%$ in averagely curved canals and 58\% in intensively curved canals [3]. The incidence of separation of nickel-titanium files $(9.4 \%)$ while compared to that of stainless steel files ranging between $2 \%$ to $6 \%[4]$.

Factors which lead to the files separation include cyclic fatigue, torsional fatigue, instrument design and configuration, root canal preparation techniques and number of times used [5]. In the recent years in the field of Endodontics the use of rotary nickeltitanium instruments has gained increased popularity. The NiTi instruments simplify and improve the effectiveness of endodontic shaping procedures. Attempts to remove retained, separated endodontic instruments have been reported in several studies using different methods like bypassing the separated instrument and

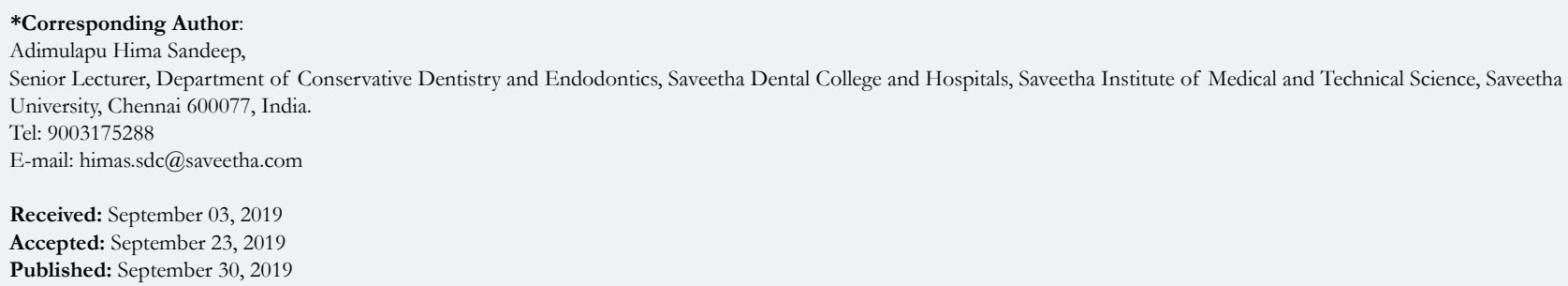

Citation: Roghith Kannan, Adimulapu Hima Sandeep, Revathi Duraiswamy. Evaluation of Rotary File Separation and its Retrieval from Root Canals - An Institutional Based Study. Int J Dentistry Oral Sci. 2019;S10:02:0016:84-89. http://dx.doi.org/10.19070/2377-8075-SI02-0100016

Copyright: Adimulapu Hima Sandeep ${ }^{\circ} 2019$. This is an open-access article distributed under the terms of the Creative Commons Attribution License, which permits unrestricted use, distribution and reproduction in any medium, provided the original author and source are credited. 
by using different devices such as endo extractor system, ultrasonics, laser, electrolytes, etc [6-8]. In certain cases surgical treatment is opted for which includes surgical removal of the fragment from the periapical tissues, bisection, root resection [9].

Instrumentation and obturation of the root canal should take place before the surgery so that the microbial flora in the root canal is significantly reduced. However in cases where successful removal of the separated file is seen, complications in the removal procedure might result in loss of considerable tooth structure and lead to complications such as root perforation [10].

The use of an operating microscope and ultrasonics increase the possibility of a successful removal of the fractured instrument and reduces the risk of complications. Overall during the removal of a separated instrument all the necessary precautions should be taken so that the least possible damages are caused to the tooth and periapical tissues. The purpose of this study was to evaluate the rotary files separation and its successful retrieval from root canals based on institutional dental records.

\section{Materials and Methods}

\section{Study Setting}

The current study is an institutional based retrospective study performed at a private dental college.

\section{Ethical approval}

The necessary approvals were obtained from the Institutional Ethical committee - SDC/SIHEC/2020/DIASDATA/0619-0320.

\section{Data Collection and Tabulation}

All the case records and treatment records were obtained from the patient management software and the data collected was cross verified by an examiner to avoid any missing case records. A total of 86,000 case sheets were verified for root canal treatment data and in which 6475 subjects have undergone root canal treatment in various teeth. Out of 6475 cases, 22 subjects who underwent rotary file separation and its retrieval were chosen carefully verify- ing the data and history. All the data collected was formatted and tabulated using Microsoft Excel ( Version - 2020). The dependent variable was rotary file separation during endodontic therapy.

\section{Inclusion Criteria}

The Inclusion criteria was patients undergoing root canal treatment in various teeth and with a fractured instrument.

\section{Exclusion Criteria}

The exclusion criteria was missing or incomplete data and also eliminated cases that were not approved by the concerned faculty in the hospital.

\section{Statistical Analysis}

The statistical analysis was performed using IBM SPSS (Version - 24). Descriptive statistics was performed to present the age distribution, gender distribution of patients, tooth involved and the site of root canal involved. Chi square test was done, to associate between tooth groups and site of instrument fracture and age groups and site of instrument fracture.

\section{Results and Discussion}

In the present study which included 22 patients, $45.50 \%$ (10) males and $54.50 \%$ (12) females have undergone rotary file retrieval treatment (Figure 1). The most common tooth group with rotary file separation and retrieval was found to be in lower molars $(36.36 \%)$, which was followed by both upper molars and upper anteriors (22.73\%) and the least being lower anteriors (18.18\%) (Figure 2). The most common site with instrument separation was found to be in both coronal third and middle third (40.91\%) and the least being apical third (18.18\%) (Figure 3). Out of 22 patients who had undergone rotary file separation and retrieval, the age group commonly identified were of $31-40$ years $(47.62 \%)$, which was followed by $41-50$ years (23.81\%), which was followed by 20 30 years $(19.05 \%)$ and the least being in the age group of $51-60$ years $(9.52 \%)$ (Figure 4$)$. (18.18\%) in lower molars had instrument separation in the middle and coronal third, $(9.09 \%)$ in upper molars had instrument separation in middle and coronal third and

Figure 1. Bar graph depicts the frequency of males and females who had undergone instrument retrieval treatment. $\mathrm{X}$ axis represents the gender of patients and $\mathrm{Y}$ axis shows the percentage of patients undergone instrumental retrieval treatment. The results show the highest number subjected to rotary file separation and its retrieval from canals was seen in females (red) $54.55 \%$ compared to males (blue) $45.45 \%$.

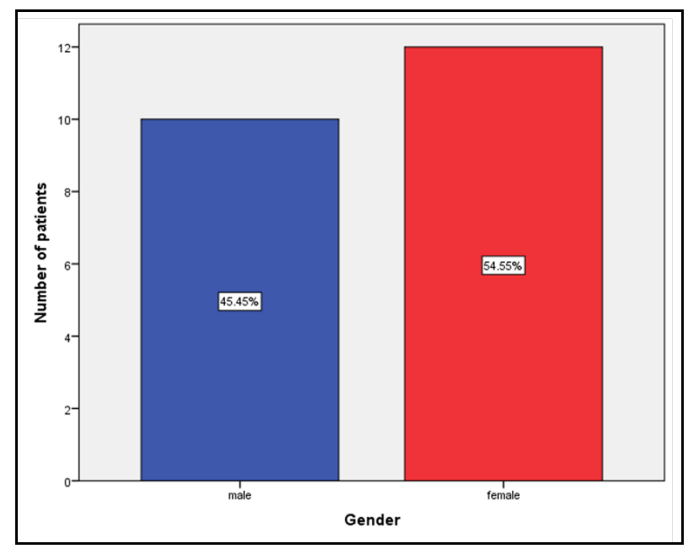


Figure 2. Bar graph depicts the frequency of various tooth groups involved in rotary file separation and its retrieval from canals. $\mathrm{X}$ axis shows the various tooth groups involved in rotary file separation and its retrieval from canals where $\mathrm{Y}$ axis shows the number of teeth. The results show the highest incidence of rotary file separation and its retrieval from canals was seen in lower molars with $36.36 \%$ (green).

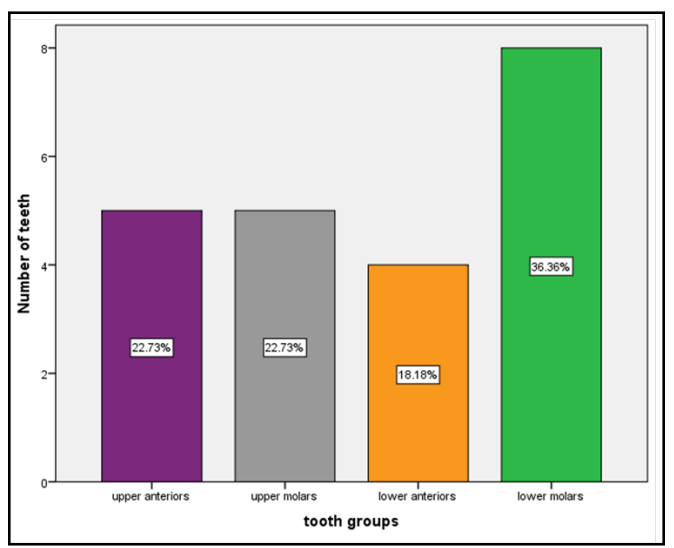

Figure 3. Bar graph depicts the frequency distribution based on the site of rotary file separation. $\mathrm{X}$ axis represents the site of rotary file separation and $\mathrm{Y}$ axis shows the number of teeth. These results show that the instrument fracture site was seen in both middle third $(40.91 \%$, red) and coronal third $(40.91 \%$, yellow) of the root canal.

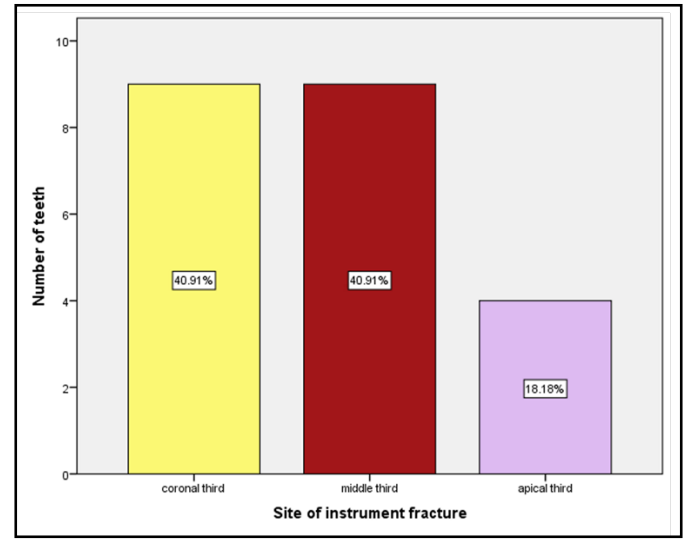

$(4.55 \%)$ in the apical third. $(9.09 \%)$ in upper anteriors had instrument separation in apical and coronal third and (4.55\%) in middle third. (4.55\%) in lower anteriors had instrument separation in apical and coronal third and (9.09\%) in middle third (Figure 5). Results show the highest incidence of instrument fracture site was seen in lower molars equally in the coronal and middle third with $(18.18 \%)$ compared to other tooth groups. No significant association was seen between tooth groups and site of instrument fracture. Chi-square test was performed and was found to be statistically not significant $(\mathrm{p}=0.668 ; \mathrm{p}>0.05)$. Patients in the age group of $31-40$ years, the site of fractured instruments was seen in coronal third $(23.81 \%)$, middle third (14.29\%) and apical third $(9.52 \%)$. Patients in the age group of $41-50$ years, the site of fractured instruments was seen in coronal third (14.29\%), middle third and apical third $(4.76 \%)$. Patients in the age group of $20-30$ years, the site of fractured instruments was seen in coronal third and apical third $(4.76 \%)$ and middle third $(9.52 \%)$. Patients in the age group of 51-60 years, the site of fractured instruments was seen in middle third $(9.52 \%)$. Results show the highest incidence of instrument fracture site was seen in the age group of 31-40 years in the coronal third with $(23.81 \%)$ compared to other age groups (Figure 6). No significant association was seen between age groups and site of instrument fracture. Chi-square test was performed and was found to be statistically not significant $(\mathrm{p}=$ $0.564 ; \mathrm{p}>0.05)$.
From the result obtained in this study we observed that instrument separation and rotary file retrieval had a higher prevalence rate in molar tooth groups and the lowest incidence occurring in the lower anteriors. Due to the complex anatomical canal configuration and curvature, the tendency of the rotary file separation is found to be greater in the molar tooth groups when compared to other tooth groups which is in correlation with our study.

Introduction of Niti instruments in Endodontics was to facilitate root canal instrumentation as well as to minimize procedural errors. The flexibility and superior resistance to torsional forces in NiTi files are three times more than the stainless steel counter parts [11]. In a study conducted by Saad al Nazhan, it was observed that the separated instruments were found more in mandibular molars, followed by maxillary molars and premolars [2] which was in correlation to our results, this is due to the severe curvature of the canal and is very important to know for better outcome of root canal cleaning and shaping procedure.

The degree of root canal curvature which was radiographically studied by Scafer et al., [12] in 700 extracted teeth due to the extensive curvature, fracture susceptibility of the instrument is increased as there is maximum stress exerted around the curved canal. Leaving the fragment of the instrument in the root canal will complicate the chemico - mechanical cleaning and filling procedure. Care should be taken not to perforate or reduce the root 
Figure 4. Bar graph depicts the frequency distribution of age groups involved in rotary file separation and its retrieval from canals. $\mathrm{X}$ axis shows the various age groups involved in rotary file separation and its retrieval from canals; $\mathrm{Y}$ axis shows the number of teeth. The results show that the rotary file separation and its retrieval was common in the age group of 31-40 years with $47.62 \%$ (black).

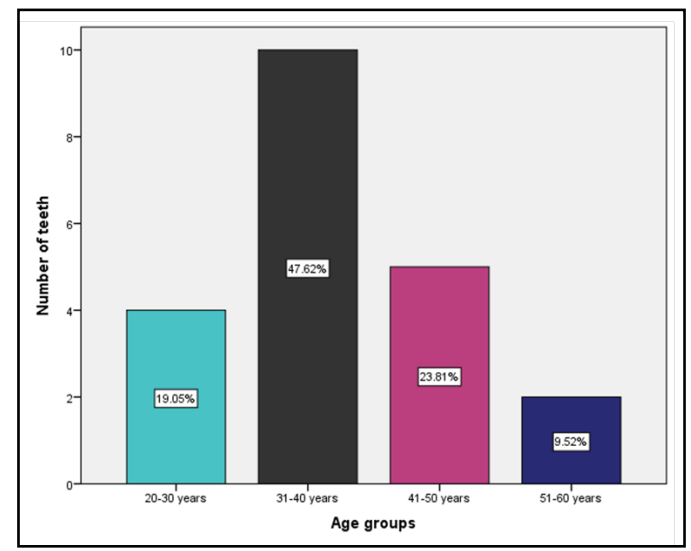

Figure 5. Bar graph depicts the association between various tooth groups and site of instrument fracture. $\mathrm{X}$ axis represents the various tooth groups involved in rotary file separation and its retrieval from canals and $\mathrm{Y}$ axis shows the number of teeth. Chi-square test was performed and there was no statistically significant association between tooth groups and site of instrument fracture (Pearson chi square value: 4.064 ; df:6; p-value: $0.668>0.05$ ). However, instrument separation and its retrieval was commonly seen in relation to lower molars from the coronal $(18.18 \%$, red) or middle third $(18.18 \%$, yellow) of the root canal.

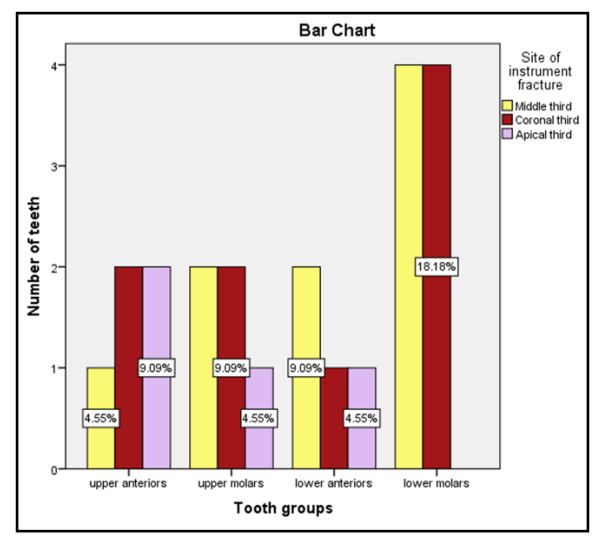

Figure 6. Bar graph depicts the association between various age groups and site of instrument fracture. $\mathrm{X}$ axis represents the various age groups; $\mathrm{Y}$ axis shows the number of teeth. Chi-square test was performed and there was no statistically significant association between age groups and site of instrument fracture (Pearson chi square value: 4.842 ; df:6; p-value: $0.564>0.05)$. However, instrument fracture and its retrieval was common among the age group of 31-40 years from the coronal third of the root canal $(23.81 \%$, red $)$.

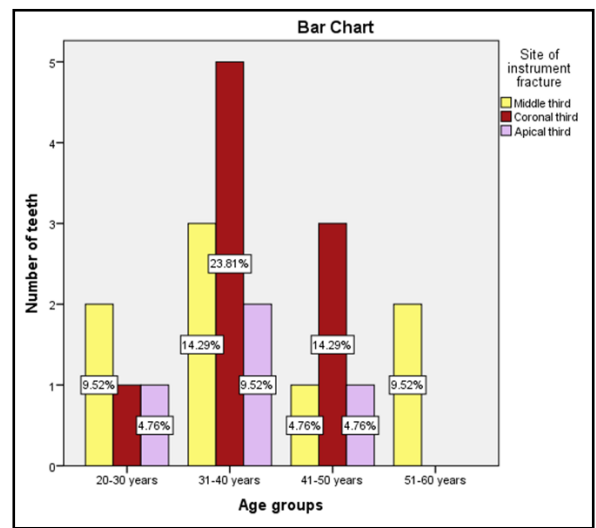

strength when an attempt is made to bypass or remove the fragmented instrument [13].

Several methods and devices including pliers, microtubes. ultrasonics have been used to remove the separated instruments with varying success rate. In a case done by Akshay Khandelal from our institution, the retrieval of the fractured instrument was done using ultrasonics under a dental operating microscope (Figure 7), similar techniques and armamentarium have been used in a study done by Gupta et al., [14]. The use of a dental operating microscope is very helpful throughout the procedure to inspect the instrument and avoid mistakes that might jeopardise the outcome 
Figure 7. (a) Radiograph showing the separated rotary file in the palatal canal in relation to 17; (b) retrieved instrument from the canal; (c) Radiograph of 17 after retrieval of the instrument; (d) Post obturation radiograph 17 (Courtesy; Dr. Akshay Khandelwal).

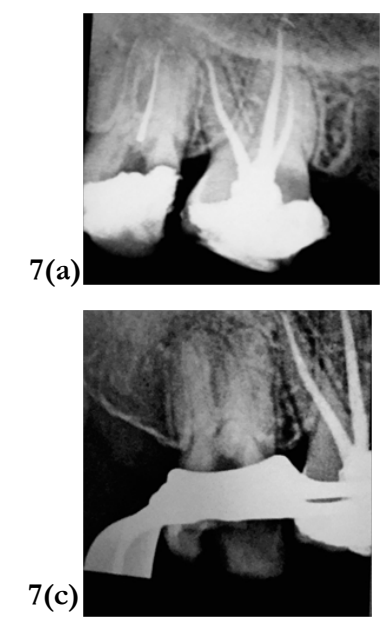

[15]. Reports of earlier studies showed that the prognosis of root canal therapy will be altered if the fragment is left in the canal. Especially with the presence of periapical pathosis. However in general, bypassing or leaving the fragment without total removal might be considered as part of the root canal filling but the status of the root canal in the presence of the fragment will play an important role in the outcome of therapy [16]. Previously our team had conducted numerous clinical trials [17-19], in vitro studies [20-24] and surveyed [25,26] and reviewed various aspects of endodontics and conservative dentistry over the past five years [27-31]. Now we are focusing on retrospective studies, the idea for which has stemmed from the current interest in our community.

\section{Conclusion}

Within the limitations of the study, it was concluded that rotary file separation and its retrieval from the root canals were identified most commonly in mandibular molars. Considering the site involved, rotary file separation and its retrieval was common in the middle third and coronal third of the root canals. Among the patients who had instrument separation and its successful retrieval, majority of the patients were female patients and patients in the age group of 31-40 years. Tooth involved and the age of the patient did not influence the site of rotary file separation and its retrieval from root canal. Care should be taken when dealing with instrument fragments in a curved canal to avoid procedural mishap. The development in technology, advanced armamentarium, and expertise enable successful management of fractured instruments.

\section{Author Contribution}

Roghith Kannan carried out the retrospective study, collection and analysis of data and drafted the manuscript. Dr Adimulapu Hima Sandeep designed the study and participated in data analysis verification and drafting the manuscript. Dr Revathi D aided in supervision and appraisal of the manuscript.

\section{Acknowledgements}

We thank Saveetha Dental College and Hospitals, Chennai for access to the retrospective data and Dr Akshay Khandelwal for

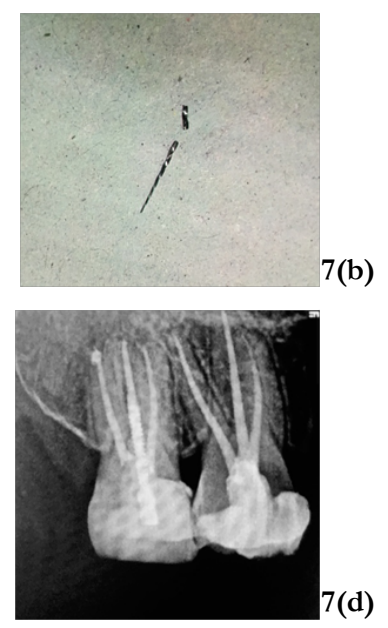

providing case records.

\section{References}

[1]. D'Arcangelo C, Varvara G, De Fazio P. Broken instrument removal--two cases. J Endod. 2000 Jun;26(6):368-70.Pubmed PMID: 11199757.

[2]. Al-Nazhan S, Al-Attas MH, Al-Maflehi N. Retrieval outcome of separated endodontic instruments by Saudi endodontic board residents: A Clinical retrospective study. Saudi Endod. J. 2018 May 1;8(2):77.

[3]. Suter B, Lussi A, Sequeira P. Probability of removing fractured instruments from root canals. Int Endod J. 2005 Feb;38(2):112-23.Pubmed PMID: 15667633.

[4]. Hülsmann M, Schinkel I. Influence of several factors on the success or failure of removal of fractured instruments from the root canal. Dent Traumatol. 1999 Dec;15(6):252-8.

[5]. Crump MC, Natkin E. Relationship of broken root canal instruments to endodontic case prognosis: a clinical investigation. J Am Dent Assoc. 1970 Jun;80(6):1341-7.Pubmed PMID: 5266127.

[6]. Gettleman BH, Spriggs KA, ElDeeb ME, Messer HH. Removal of canal obstructions with the Endo Extractor. J Endod. 1991 Dec;17(12):608-11. Pubmed PMID: 1820424.

[7]. Madarati AA, Hunter MJ, Dummer PM. Management of intracanal separated instruments. J. Endod. 2013 May 1;39(5):569-81.

[8]. Ormiga F, da Cunha Ponciano Gomes JA, de Araújo MC. Dissolution of nickel-titanium endodontic files via an electrochemical process: a new concept for future retrieval of fractured files in root canals. J Endod. 2010 Apr;36(4):717-20.Pubmed PMID: 20307750.

[9]. Ward JR. Risk Management In Root Canal Treatment; Th. P. Lambrianidis. Aust. Dent. J. 2002 Aug;28(2):86.

[10]. Souter NJ, Messer HH. Complications associated with fractured file removal using an ultrasonic technique. J Endod. 2005 Jun;31(6):450-2.Pubmed PMID: 15917685.

[11]. Walia HM, Brantley WA, Gerstein H. An initial investigation of the bending and torsional properties of Nitinol root canal files. J Endod. 1988 Jul;14(7):346-51.Pubmed PMID: 3251996.

[12]. Schäfer E, Diez C, Hoppe W, Tepel J. Roentgenographic investigation of frequency and degree of canal curvatures in human permanent teeth. J Endod. 2002 Mar;28(3):211-6.Pubmed PMID: 12017184.

[13]. Sjögren UL, Hägglund B, Sundqvist G, Wing K. Factors affecting the longterm results of endodontic treatment. J. Endod. 1990 Oct 1;16(10):498504.

[14]. Gupta R, Sharma T, Charles NSC, et al. CLINICAL APPROACH TO THE MANAGEMENT OF FRACTURED INSTRUMENTS USING ULTRASONICS AND THE INSTRUMENT RETRIEVAL SYSTEM UNDER THE DENTAL OPERATING MICROSCOPE. International Journal of Medical and Biomedical Studies; 4.

[15]. Ward JR, Parashos P, Messer HH. Evaluation of an ultrasonic technique to remove fractured rotary nickel-titanium endodontic instruments from root canals: clinical cases. J Endod. 2003 Nov;29(11):764-7.Pubmed PMID: 14651286.

[16]. Simon S, Machtou P, Tomson P, Adams N, Lumley P. Influence of fractured instruments on the success rate of endodontic treatment. Dent Update. 2008 
Apr;35(3):172-179.Pubmed PMID: 18507225.

[17]. Ramamoorthi S, Nivedhitha MS, Divyanand MJ. Comparative evaluation of postoperative pain after using endodontic needle and EndoActivator during root canal irrigation: A randomised controlled trial. Aust Endod J. 2015 Aug;41(2):78-87.Pubmed PMID: 25195661.

[18]. Hussainy SN, Nasim I, Thomas T, Ranjan M. Clinical performance of resinmodified glass ionomer cement, flowable composite, and polyacid-modified resin composite in noncarious cervical lesions: One-year follow-up. J Conserv Dent. 2018 Sep-Oct;21(5):510-515.Pubmed PMID: 30294112.

[19]. Janani K, Palanivelu A, Sandhya R. Diagnostic accuracy of dental pulse oximeter with customized sensor holder, thermal test and electric pulp test for the evaluation of pulp vitality: an in vivo study. Braz. Dent. Sci. 2020 Jan 31;23(1):8-p.

[20]. Ramanathan S, Solete P. Cone-beam Computed Tomography Evaluation of Root Canal Preparation using Various Rotary Instruments: An in vitro Study. J Contemp Dent Pract. 2015 Nov 1;16(11):869-72.

[21]. Siddique R, Sureshbabu NM, Somasundaram J, Jacob B, Selvam D. Qualitative and quantitative analysis of precipitate formation following interaction of chlorhexidine with sodium hypochlorite, neem, and tulsi. J Conserv Dent. 2019 Jan-Feb;22(1):40-47.Pubmed PMID: 30820081.

[22]. Rajendran R, Kunjusankaran RN, Sandhya R, Anilkumar A, Santhosh R, Patil SR. Comparative Evaluation of Remineralizing Potential of a Paste Containing Bioactive Glass and a Topical Cream Containing Casein Phosphopeptide-Amorphous Calcium Phosphate: An in Vitro Study. Pesqui. Bras. Odontopediatria Clín. Integr. 2019;19:1-10.

[23]. Teja KV, Ramesh S, Priya V. Regulation of matrix metalloproteinase-3 gene expression in inflammation: A molecular study. Journal of conservative dentistry: JCD. 2018 Nov;21(6):592-596.

[24]. Nandakumar M, Nasim I. Comparative evaluation of grape seed and cranberry extracts in preventing enamel erosion: An optical emission spectrometric analysis. J Conserv Dent. 2018 Sep-Oct;21(5):516-520.Pubmed PMID: 30294113.

[25]. Jose J, Subbaiyan H. Different Treatment Modalities followed by Dental Practitioners for Ellis Class 2 Fracture-A Questionnaire-based Survey. Open Dent. J. 2020 Feb 18;14(1):59-65.

[26]. Manohar MP, Sharma S. A survey of the knowledge, attitude, and awareness about the principal choice of intracanal medicaments among the general dental practitioners and nonendodontic specialists. Indian J Dent Res. 2018 Nov-Dec;29(6):716-720.Pubmed PMID: 30588997.

[27]. Rajakeerthi R, Ms N. Natural Product as the Storage medium for an avulsed tooth-A Systematic Review. Cumhur. Dent. J. 2019;22(2):249-56.

[28]. Kumar D, Antony S. Calcified Canal and Negotiation-A Review. Res J Pharm Technol. 2018;11(8):3727-30.

[29]. Ravinthar K. Recent advancements in laminates and veneers in dentistry. Res J Pharm Technol. 2018;11(2):785-7.

[30]. Noor S. Chlorhexidine: Its properties and effects. Res J Pharm Technol. 2016;9(10):1755-60.

[31]. Janani K, Palanivelu A, Sandhya R. Diagnostic accuracy of dental pulse oximeter with customized sensor holder, thermal test and electric pulp test for the evaluation of pulp vitality: an in vivo study. Braz. Dent. Sci. 2020 Jan 31;23(1):8. 